Review Article

\title{
PRACTICAL APPROACH TO GREEN CHEMISTRY
}

\author{
MEENA BHANDARI*, SEEMA RAJ \\ Department of Chemistry, School of Basic and Applied Sciences, K. R. Mangalam University, Sohna Road, Gurgaon, Haryana, India \\ Email: meena.bhandari@krmangalam.edu.in
}

Received: 13 Oct 2016 Revised and Accepted: 14 Feb 2017

\begin{abstract}
The basic principles of green chemistry addresses various issues related to synthesis of chemical compounds: planning organic synthesis to maximise yield, prevention/minimization of waste, atom economy, the use of less lethal chemicals, use of safer solvents, renewable starting materials, energy efficiency and use of green catalysts. The objective of this study is to elaborate the practical approach of green methods. In this paper, we elucidate some important common syntheses having green procedures which can be used in the fields of pharmaceutical chemistry and other fields as well. Green chemistry principles follow up to reduce pollution and environmental degradation by utilizing eco-friendly, nonhazardous, reproducible and efficient solvents and catalysts in the synthesis of drug molecules, drug intermediates and in researches involving synthetic chemistry. The paper also approaches green methods in which microwave radiation can be used as an energy efficient tool. Experimental procedures are gathered from educational journals and laboratory manuals and are viewed in the light of efficacy of green chemistry principles.
\end{abstract}

Keywords: Green chemistry, Organic syntheses, Solvents, Laboratory, Reduce pollution

(C) 2017 The Authors. Published by Innovare Academic Sciences Pvt Ltd. This is an open access article under the CC BY license (http://creativecommons.org/licenses/by/4. 0/) DOI: http://dx.doi.org/10.22159/ijpps.2017v9i4.15640

\section{INTRODUCTION}

The concept of 'Green Chemistry' introduced in the middle of $29^{\text {th }}$ century, has caught the imagination of all chemists. Convincing chemists to think in an environmentally friendly manner begins with education. However, while we enthusiastically teach and illustrate the twelve principles of green chemistry in theory but we do not follow them in our labs. Here we present at some of the issues involved in performing experiments in the labs by the conventional methods and recommend some simple processes which could improve our laboratory functioning.

Green chemistry is defined as environmentally benign chemistry, which aims to design new chemical methods/products that can reduce environmental pollution. Its objective is to target pollution at the design stage, even before it begins. If chemists are taught to synthesise products and materials without using hazardous substances, then much waste, hazards and cost can be evaded.

Ever since the twelve principles of green chemistry were introduced by Anastas and Warnerin 1998, a lot of work has been done for evolving green procedures for various chemical reactions. A large amount of work is published [1-4] and journals like Green Chemistry, Green Chemistry Letters and Reviews, etc. are also devoted to this area of research.

Our quality of life has improved significantly through chemistry as it has provided us various useful products but this achievement has also resulted into a deprivation of global environment and decline in non-renewable natural resources. Many pollutants end up their way to the food chain and deteriorate the ecosystem. Pesticides and fertilizers residues from agriculture farms, flame retardants from electronics and oil from oil spillage/blast commonly affect the aquatic organisms, especially marine animals. Sustainability is at stake and the quality of life is under great threat.

Green chemistry and its principles can change all these negative impacts and through design, innovative and green practices to reestablish the planet's sustainable development. The term "sustainable chemistry" proposed initially was changed into "green" because it means drastic change, a refutation of old attitudes and practices, innovation and design of newer methods/products. The ultimate goal is to develop and design unconventional synthetic methodologies for important industrial chemicals in order to prevent/reduce environmental pollution.
The twelve principles of green chemistry $[3,4]$ are depicted in following fig. 1 which helps to explain their significance.

Green chemistry approach plays a vital role in:

- Pollution prevention by improved operational practices by lowering energy consumption, improving yields.

- Development of greener processes to manufacture unchanged chemical products by avoiding the use of chlorinated compounds/ solvents if chlorine is not in the final product.

- Formulation of alternative chemicals for the same application.

- Avoidance of chemicals and also use of chemistry for improved environmental performance by designing chemical sensors for better observation of environmental quality.

Sustainable and green chemistry in simple terms is just a different approach for chemists and chemical engineers which enable scientists and engineers to protect and help the economy, people and the planet by finding imaginative and innovative ways to reduce waste, conserve energy, and discover replacements for harmful substances. The scope of these green chemistry and engineering principles go beyond apprehensions over hazards from injurious chemicals and include energy conservation and waste reduction, as well as the use of more sustainable or renewable feedstock and safe designing for the product as well as its final disposition.

But how many under graduate labs, till date follows the abovementioned principles of green chemistry? Undergraduate chemistry students have been doing the same labs in a conventional manner for decades. Updates to reactions, titrations, extractions, and other conventional teaching experiments have not been widely executed despite the use of lethal solvents, overly reactive reagents, and unnecessary waste generation. Chemistry labs generate a large amount of toxic liquids and solid waste and in many organic reactions like nitration, bromination and sulphonation, thick fumes and noxious odors are also generated, causing pollution and impacting the health of students and faculty. The effect becomes all the more large as the labs are becoming air conditioned now a day. So the fumes generated in the chemistry labs not only affect the students working in the laboratories but will affect all the students in the campus as the air present in the lab will be sucked and recirculate. Furthermore, experiments are performed on a large scale leading to wastage of chemicals, water and electricity. Spent chemicals and solvents are thrown into the drain 
leading to water pollution. The importance of using green chemistry can easily be brought about by explicitly connecting green chemistry teaching with the promotion of sustainable development by the involvement of younger generation.
It is definitely essential for realizing sustainability to integrate green chemistry in the teaching of chemistry, and in this context, students should be made aware of the significance and hitches for augmenting the greenness of chemical reactions [5].

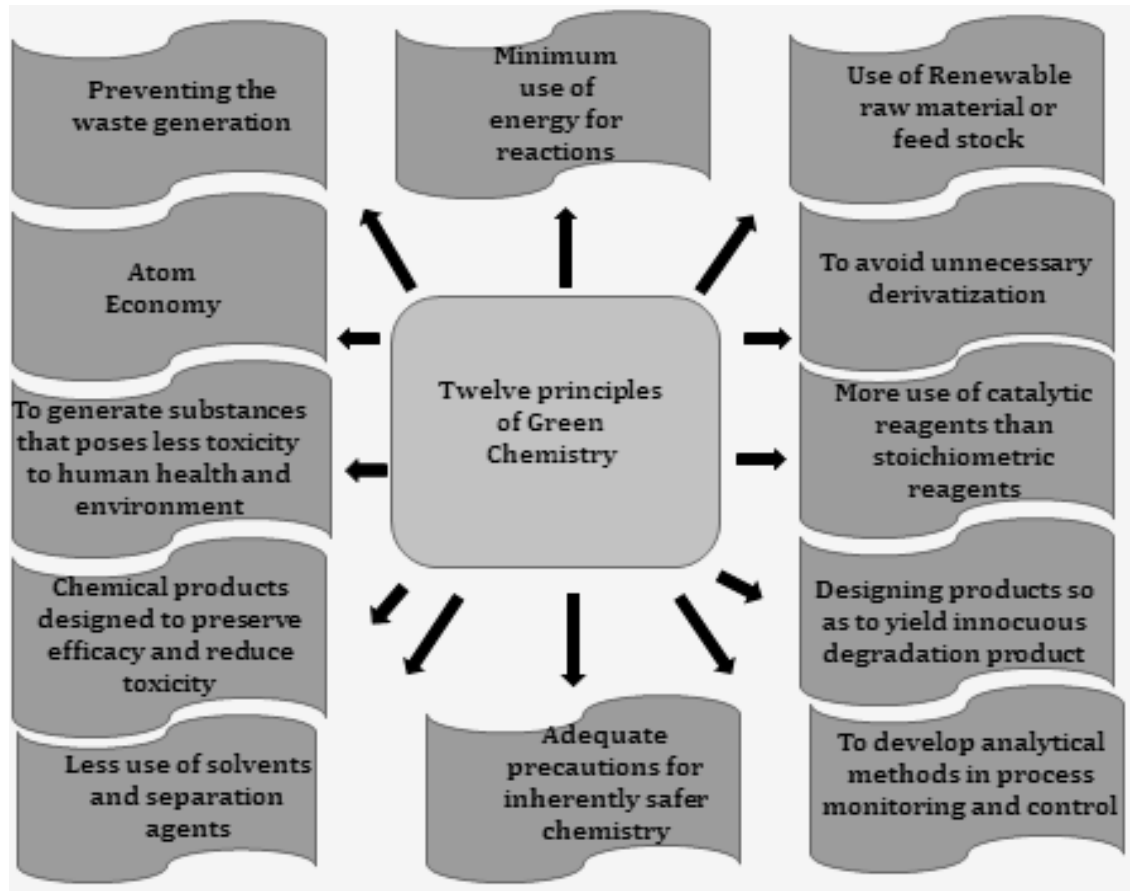

Fig. 1: The twelve principles of green chemistry $[3,4]$

Changes in the organic synthetic methodologies will not only address health and safety issues in the small scale laboratory but will also affect the large industrial scale production processes through the new techniques.

Though there are a large number of organic green syntheses is available in literature, but we have chosen few which can be part of the undergraduate curriculum. In this regard, we will like to mention that many organic chemistry experiments as mentioned below performed in the labs through green methods, produced good yield without producing any hazardous wastes and can easily be incorporated in the labs for undergraduate students. These processes involve the use of green reagents, green catalysts, green solvents and emerging green technologies like microwave chemistry, sonochemistry and photochemistry, etc. and will help students to have hands-on experience with new methodologies as well as to change their attitude and understanding regarding green procedures/green approaches.

\section{Less hazardous chemical syntheses/inherently safer chemistry} for accident prevention

The main focus of green chemistry is to make the environment safer not only for the general public but also for manufacturing or laboratory worker through the use of safer materials and processes. Wherever practicable, synthetic methods should be planned in such a way so as to use and produce substances that pose little or no toxicity to human health and the environment. Substances or chemicals to be used in a chemical process should be chosen with care to lessen the potential for chemical accidents/explosions and fires. Chemists use toxic substances all the time because these chemicals result into kinetically and thermodynamically favorable reactions. It's easy not to worry about all the other "stuff" going into the flask and put all our effort on the synthetic pathway that delivers the desired product. If new replacement chemicals along with new synthetic procedures are not established, inherently toxic materials will continue to be used. Chemists are required to broaden their horizon and try to do reactions by using unique less lethal materials otherwise; we will have to pay the price in terms of environmental degradation.
We, mention some of the reactions where toxic reagents have been replaced by environmentally friendly/safe reagents.

\section{Bromination reactions}

\section{Electrophilic substitution reactions}

Aromatic electrophilic bromination reaction is a fundamental and useful reaction. The aromatic bromo-compounds can act as potent antitumor, antibacterial, antifungal, antineoplastic, antiviral and anti-oxidizing agent [6]. Moreover, the aromatic bromo compounds are an important precursor for grignard reagents [2].

Bromination of acetanilide using cericammonium nitrate and potassium bromide

The conventional procedure for bromination involves use of corrosive molecular bromine i.e. a toxic species which causes serious burns. Its use generate grave complications with regard to its handling and disposal, especially in large scale and commercial applications which have been replaced with a novel brominating agent (ceric ammonium nitrate and potassium bromide) [7, 8]. In addition, it provides benefits i.e. greater solubility in water, less cost, eco-friendly nature, easy handling, high reactivity, and easy work-up procedures. Furthermore, bromination is carried out in aqueous medium evading the use of chlorinated solvents.

In a conical flask acetanilide $(1 \mathrm{~g}, 0.008 \mathrm{~mol})$ was dissolved in ethanol $(15 \mathrm{ml})$. Then potassium bromide $(1 \mathrm{~g}, 0.008 \mathrm{~mol})$ and ceric ammonium nitrate $(6 \mathrm{~g}, 0.011 \mathrm{~mol})$ were dissolved in water $(15 \mathrm{ml})$. This solution was added dropwise to the reaction vessel containing acetanilide solution (Scheme 1). After the addition was over, the reaction mixture was stirred for $10 \mathrm{~min}$ at ambient temperature. White crystals appeared when this solution was poured into ice-cold water. The white crystals of p-bromo acetanilide were filtered, and the solid was dried (1.34 g, $85 \%$ yield) having a melting point $165^{\circ} \mathrm{C}$. 
<smiles>O=CCNc1ccccc1</smiles>

(1) $\mathrm{CAN}, \mathrm{KBr}, \mathrm{H}_{2} \mathrm{O}, \mathrm{EtOH}$

(2) $\mathrm{KBr} / \mathrm{CAN} / \mathrm{PEG}^{-} 400$ $50^{\circ} \mathrm{C}$

Acetanilide<smiles>CC(=O)Nc1ccc(Br)cc1</smiles>

4-Bromoacetanilide

(Scheme 1)

A quick, eco-friendly and chemo-regio selective method for the bromination of aromatic compounds has been developed where $\mathrm{Br}^{+}$ is generated in situ from potassium bromide $(\mathrm{KBr})$ using ceric ammonium nitrate (CAN) as the lewis acid catalyst in PEG-400 (Polyethylene glycol) and the products are obtained in highly excellent yields which do not require any further purification [9].

In a typical method, a solution of ceric ammonium nitrate $\left(1.3^{*} 10^{-3} \mathrm{~mol}\right)$ and $\mathrm{KBr}\left(0.75^{*} 10^{-3} \mathrm{~mol}\right)$ in PEG $(15 \mathrm{ml})$ was added dropwise to the solution of arenes $\left(0.5^{*} 10^{-3} \mathrm{~mol}\right)$ in PEG $(10 \mathrm{ml})$ and the mixture was stirred at $50{ }^{\circ} \mathrm{C}$ (Scheme 1)]. After the addition was over, the reaction mixture was further stirred for additional 10-15 min. White crystals appeared after pouring the hot mixture over ice cold water. The white crystals were filtered and the solid was dried (yield $89 \%, \mathrm{~m}$. p. $=169^{\circ} \mathrm{C}$ ).

Sodium bromide in the presence of $1 \mathrm{M}$ hydrochloric acid $(\mathrm{HCl})$ with common household bleach produces bromine in situ which shows aromatic electrophilic substitution reaction selectively in good yield under mild reaction conditions as reported by Halder in 2012 [10]. This is a very economical, sophisticated, water-based method as described below:

\section{Bromination of aromatic compounds using $\mathrm{NaBr}, \mathrm{HCl}$ and $\mathrm{NaOCl}$}

In a round bottom flask, sodium bromide $(\mathrm{NaBr})\left(0.823 \mathrm{~g}, 8^{*} 10^{-3}\right.$ mol) and hydrochloric acid ( $\mathrm{HCl})(7 \mathrm{ml}, 1 \mathrm{M})$ were added over acetanilide $\left(1 \mathrm{~g}, 7.4^{*} 10^{-3} \mathrm{~mol}\right)$ in aqueous alcohol and the mixture was stirred rapidly. Then the addition of sodium hypochloride $(\mathrm{NaOCl})(5 \mathrm{ml}, 4 \% \mathrm{w} / \mathrm{v})$ was made dropwise through a pressure equalizer for an about $75 \mathrm{~min}$. After each addition, a yellow precipitate appeared which soon disappeared. An off-white precipitate of 4-bromoacetanilide was filtered, washed with dilute sodium bisulphite solution and then with water and was recrystallized from ethyl alcohol (95\%) having yield 1.56g, 98\% with m. p.169-170 ${ }^{\circ} \mathrm{C}[10]$.

\section{Addition of bromine across double bond}

The conventional procedure involves use of liquid bromine in chlorinated solvents (dichloromethane- $\mathrm{CH}_{2} \mathrm{Cl}_{2}$ ), which has been replaced by hydrobromic acid $(\mathrm{HBr})$ and hydrogen peroxide $\left(\mathrm{H}_{2} \mathrm{O}_{2}\right)$. The below-mentioned procedure is not only atom efficient but also generates water as by-product.

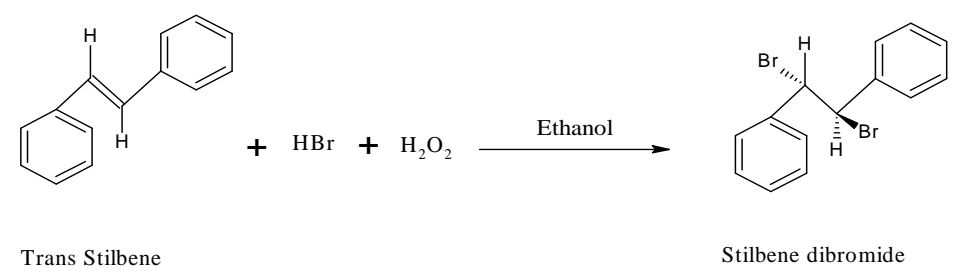

(Scheme 2)

\section{Bromination of trans-stilbene using $\mathrm{HBr}$ and $\mathrm{H}_{2} \mathrm{O}_{2}$}

The aqueous solution of hydrobromic acid (33\%, $5.2 \mathrm{ml})$ and hydrogen peroxide $(30 \%, 7 \mathrm{ml})$ were added through a dropping funnel to the refluxing solution of trans-stilbene $(1.80 \mathrm{~g}, 0.01 \mathrm{~mol})$ in ethanol $(10 \mathrm{ml})$ (Scheme 2). The colorless solution became deep orange in color which disappeared within $15 \mathrm{~min}$, indicating the completion of reaction. The solution was allowed to cool down and the precipitates separated out. These precipitates were filtered, recrystallized and dried having melting point $237^{\circ} \mathrm{C}$ in $70 \%$ yield (2.4 gm) [11].

\section{Bromination of trans-stilbene using $\mathrm{NaBr}$ and $\mathrm{NaOBr}$}

To a solution of trans-stilbene $(1.8 \mathrm{~g}, 0.01 \mathrm{~mol})$ in glacial acetic acid $(20 \mathrm{ml})$ was added a mixture of sodium bromide $(3 \mathrm{~g}, 0.029$ mol) and sodium bromate ( $1 \mathrm{~g}, 0.008 \mathrm{~mol})$ at room temperature with occasional stirring by a glass rod for 1 hour. The light brown color which developed during stirring disappeared. The acetic acid present in the reaction mixture was neutralized by the addition of sodium hydroxide solution. The precipitate of stilbene dibromide were filtered and dried to give $80 \%$ yield ( $2.6 \mathrm{~g}$ ) [7].

\section{Nitration reactions}

\section{Nitration of Salicylic acid using calcium nitrate and acetic acid}

The conventional procedure involves use of sodium nitrate $\left(\mathrm{NaNO}_{3}\right)$ and concentrated sulphuric acid $\left(\mathrm{H}_{2} \mathrm{SO}_{4}\right)$ which has been replaced by calcium nitrate $\left[\mathrm{Ca}\left(\mathrm{NO}_{3}\right)_{2}\right]$ and acetic acid to get regio-selective products.<smiles>O=C(O)c1ccccc1O</smiles>

Salicylic Acid<smiles>O=C(O)c1cc([N+](=O)[O-])ccc1O</smiles>

4 -nitrosalicylic acid

(Scheme 3) 
Calcium nitrate $(1.5 \mathrm{~g}, 0.009 \mathrm{~mol})$ was dissolved in warm acetic acid $(5 \mathrm{ml})$ and salicylic acid $(1 \mathrm{~g}, 0.007 \mathrm{~mol})$ was added to it and the mixture was heated on a water bath (maintained at $>80^{\circ} \mathrm{C}$ ) for $1 \mathrm{~min}$ (Scheme 3). After the dissolution of salicylic acid, the solution became dark red. It was immediately poured into ice cold water (10 $\mathrm{ml})$. The resultant turbid dark red solution was kept in a refrigerator. The yellow crystals which separated out after four hours were washed with small amount of ice-cold water to make it free from acid and then dried to yield $0.66 \mathrm{~g}(50 \%)$ of a 4 nitrosalicylic acid having a melting point at $234^{\circ} \mathrm{C}$ [12].

\section{Benzoin condensation}

Thiamine hydrochloride catalyzed synthesis of benzoin from benzaldehyde

The conventional condensation of benzaldehyde to yield benzoin involves highly poisonous sodium cyanide $(\mathrm{NaCN})$ which has been replaced by environmentally friendly thiamine hydrochloride.

To the thiamine hydrochloride $(1.75 \mathrm{~g}, 0.005 \mathrm{~mol})$, dissolved in water (about $5 \mathrm{ml}$ ) in a round-bottom flask and ethyl alcohol (95\%, $15 \mathrm{ml}$ ) was added to it and the solution was cooled in an ice water bath (Scheme 4). Meanwhile, the addition of cooled sodium hydroxide solution $(5 \mathrm{ml})$ was made dropwise to the thiamine solution over a span of about 10 min. After addition of fresh benzaldehyde $(10 \mathrm{ml}, 0.098 \mathrm{~mol})$ to this reaction mixture, heating was done on a water bath for one and a half hour. The mixture was cooled at room temperature and then in ice bath to induce crystallisation of the benzoin. If product separated as oil, the mixture was reheated until homogeneous. Then it was allowed to cool more slowly than before. To induce crystallisation, scratching of the flask with a glass rod was done. Benzoin (yield $=6 \mathrm{~g}, 30 \%$ ) with a melting point at $135^{\circ} \mathrm{C}$ was obtained [13].

\section{Safer solvents and auxiliaries/solvent-free reactivity}

Solvents and other separation agents affect the overall "greenness" of the chemical reaction. In the conventional chemistry experiments, most reactions are done in the presence of a solvent as the reactants can intermingle and react efficiently in a homogeneous solution, which expedites the stirring and the reactant molecules come near to each other promptly and uninterruptedly.

Moreover, uniform heating or cooling of the mixture, if needed, can be easily carried out in a solution. Except for solvolysis reactions, the solvent normally is not incorporated in product and is recovered unchanged after the reaction is over. So students while performing experiments generally ponder over the selectivity of a suitable solvent.

It has also been shown that solvents account for $50-80$ percent of the mass in a standard batch chemical operation. Moreover, solvents in a standard batch chemical operation are responsible for about $75 \%$ of the cumulative life cycle environmental impacts.

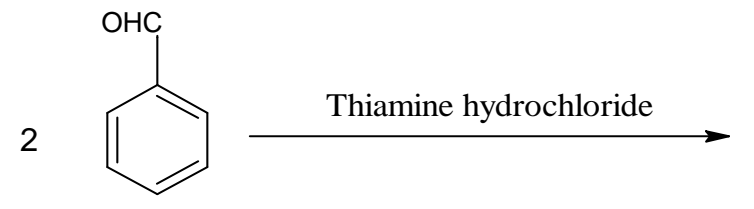

Benzaldehyde

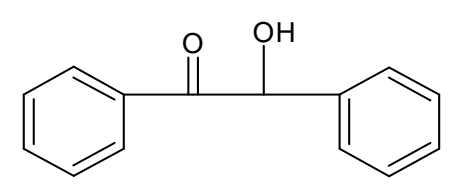

Benzoin

(Scheme 4)

Solvents and mass separation agents also consume energy in a chemical process as they may be heated, distilled, cooled, pumped, mixed, distilled under vacuum, filtered, etc. before they are recycled and if they're not recycled, they are often incinerated. Moreover, solvents are also the major contributors to the overall toxicity profile and also pose process safety issues because they are flammable and volatile, or under the right conditions, explosive.

The use of auxiliary substances (e. g., solvents, separation agents, etc.) should be made redundant wherever possible and harmless when used.

In the light of the application of the above-mentioned principle, it is possible to make better choices. However, to develop environmentfriendly synthetic procedures, chemists try to minimise or evade the use of solvents that are a major cause of pollution [14]. Vigorous research and reinvestigation of known reactions to achieve organic synthesis under the safe or solvent-free condition is going on $[15,16]$.

Remarkable research establishes that "the best solvent is no solvent" [17]. Pioneering work by Tanaka and Toda [18, 19] introduced the technique of "grindstone chemistry" [20] which is adapted for the large-scale production of pharmaceuticals. Essential activation energy is provided from contact of the reactive molecules in solvent-free conditions. Solvent-free reactions are often complete in a matter of minutes and routinely require simplistic workup and purification protocols.

Principles of green chemistry to "use safer solvents and reaction conditions" and to "prevent waste" [4] are both directly met by eliminating a reaction medium. Along with this, the principle "increase energy efficiency" is also addressed. Due to increased reactant concentrations under ambient conditions in the presence or absence of grinding, reaction rate increases in the absence of a solvent. These reactions generally occur at are room temperature by mechanical mixing; microwave/visible light irradiation and conventional heating. Solid-state reactions are more economical, do not require much purification, possess high reaction rate and are environmentally friendly. A solvent-free or solid state reaction can easily be accomplished by using the reactants alone or by incorporating them in clays, zeolites, silica, alumina, etc. to obtain stereoselective products as well as to diminish byproducts or to maximise the rate of reaction.

\section{Aldol Condensation between 3, 4-Dimethoxybenzaldehyde and 1-Indanone}

$0.250 \mathrm{~g}$ of 3, 4-dimethoxybenzaldehyde and $0.200 \mathrm{~g}$ of 1 -indanone was put into a clean, dry test tube. The two solids were ground together until they become brown oil by using a spatula. To the reaction mixture was added $0.050 \mathrm{~g}$ of finely ground solid $\mathrm{NaOH}$. Scraping and grinding were continued until the mixture becomes a solid (Scheme 5) [21-23]. The mixture was allowed to stand for about $15 \mathrm{~min}$ and the solid was put up in about 2-3 $\mathrm{ml}$ of $0.02 \mathrm{M} \mathrm{HCl}$ (aqueous). This slurry was filtered by vacuum and the product was washed with $\sim 10 \mathrm{ml}$ of water and dried using vacuum to obtain a product with a melting point $\left(178-181^{\circ} \mathrm{C}\right)$.

Dehydration of the initial aldol product leads to a conjugated enone that is recrystallized from 9:1 ethanol: water. Mixing of both solid carbonyl reactants leads to melting so that condensation occurs in the liquid state. Liquid or melt phase has been revealed to be indispensable for such aldol reactions to progress [21].

\section{Diel's Alder reaction}

Conventional method involves refluxing of furan and maleic anhydride in benzene solvent. The procedure given below involves use of water as a solvent and the reaction is $100 \%$ atom efficient. 
In a round bottom flask, a mixture of furan ( $1 \mathrm{~g}, 0.015 \mathrm{~mol}$ ), maleic acid ( $2 \mathrm{~g}, 0.017 \mathrm{~mol})$ in water $(10 \mathrm{ml})$ was stirred at room temperature for 2-3 h (Scheme 6). The adduct formed, was filtered, washed using water, dried and recrystallized from aqueous ethanol in $80 \%$ (2.1 g) yield having m. p. $138-140{ }^{\circ} \mathrm{C}$ $[24,25]$<smiles>COc1ccc(C=C2Cc3ccccc3C2=O)cc1OC</smiles>

(Scheme 5)<smiles>O=C(O)/C=C\C(=O)O</smiles>

Maleic acid

Furan

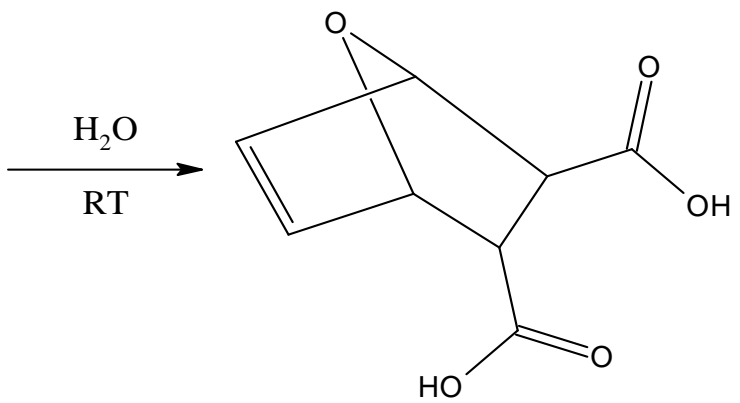

Adduct

(Scheme 6)

\section{Preparation of oximes}

Conversion of carbonyl functionalities into oximes is used as an important reaction in organic chemistry for purification and characterization of carbonyl compounds [26, 27]. Classically, oximes are prepared [27] by refluxing an alcoholic solution of a carbonyl compound with hydroxylamine hydrochloride and base usually pyridine is used as a catalyst. The method show several drawbacks such as low yields, long reaction time, the toxicity of pyridine and water pollution which occur because of the use of organic solvents.

\section{Typical procedure for the formation of oxime (2)}

A mixture of aldehyde/ketone $1\left(1^{*} 10^{-3} \mathrm{~mol}\right)$, hydroxylamine hydrochloride $\left(1.2^{*} 10^{-3} \mathrm{~mol}\right)$, and bismuth oxide $\left(\mathrm{Bi}_{2} \mathrm{O}_{3}\right)\left(0.6^{*} 10^{-3}\right.$ mol) was grounded in pestle mortar (Scheme 7). Completion of the reaction was monitored through thin layer chromatography, and ethyl acetate $(2 \times 10 \mathrm{ml})$ was added to the reaction mixture. Filtration of the reaction mixture was done to remove the $\mathrm{Bi}_{2} \mathrm{O}_{3}$. The filtrate was concentrated, and water was added which separated the product from the solution. The precipitates were filtered and dried in vacuum to give the pure oxime 2 in $60-98 \%$ yield (Scheme 7) [28].

\section{Base-catalyzed aldol condensation}

\section{Synthesis of di benzal propanone}

Base-catalyzed aldol condensation involves hazardous organic solvents and toxic reagents, but in green method given below, the reaction is done in ethanol. The condensation can be done in the presence of sodium hydroxide $(\mathrm{NaOH})$ or lithium hydroxide $(\mathrm{LiOH}$. $\mathrm{H}_{2} \mathrm{O}$ ) (Scheme 8).

\section{Synthesis of di benzal propanone in the presence of $\mathrm{NaOH}$}

Benzaldehyde ( $\left.3.8 \mathrm{ml}, 36^{*} 10^{-3} \mathrm{~mol}\right)$, acetone $(1 \mathrm{ml}, 48 \mathrm{~mol})$ and methylated sprit (or alcohol) $(15 \mathrm{ml})$ were shaken together for 2 min in a conical flask fitted with guard tube. To it was added $30 \mathrm{ml}$ of $10 \%$ sodium hydroxide solution and was shaken vigorously for 10 min with simultaneous pressure release. The cooling of the reaction mixture was done in ice and the pale yellow solid was filtered, washed with water, dried, collected, weighed [yield: $3 \mathrm{~g} \mathrm{(90 \% )]} \mathrm{and}$ recrystallized using ethanol, m. p. $\left(120-122^{\circ} \mathrm{C}\right)[29]$.

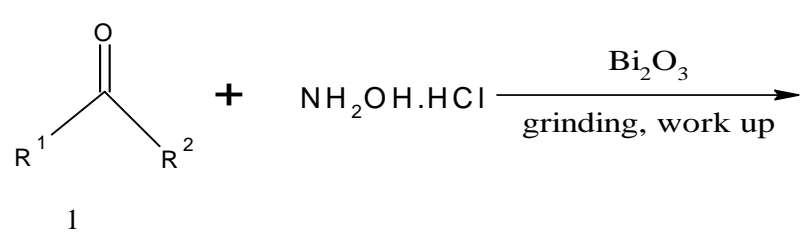

Hydroxylamine

hydrochloride

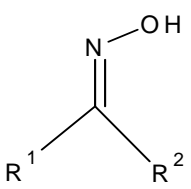

2

Oxime 
<smiles>CC(=O)CCc1ccccc1/C=C/C(=O)/C=C/c1ccccc1</smiles>

Benzaldehyde

Acetone

1,5-Diphenyl-penta-1,4-dien-3-one

(Scheme 8)

\section{Synthesis of di benzal propanone in the presence of $\mathrm{LiOH} . \mathrm{H}_{2} \mathrm{O}$}

In a $25 \mathrm{ml}$ round bottom flask containing a small magnetic bar, the benzaldehyde $\left(2.3 \mathrm{ml}, 20^{*} 10^{-3} \mathrm{~mol}\right)$ and acetone $\left(0.81 \mathrm{ml}, 11^{*} 10^{-3}\right.$ mol) were taken and ethyl alcohol $(5 \mathrm{ml})$ and lithium hydroxide monohydrate ( $42 \mathrm{mg}, 1^{*} 10^{-3} \mathrm{~mol}$ ) was added into it.

The reaction mixture was stirred vigorously for 8-10 $\mathrm{min}$ on a magnetic stirrer. Crushed ice ( $5 \mathrm{~g}$ ) was added when pale yellow solid precipitated out. The solid was allowed to settle down at the bottom. The precipitated pale yellow solid was filtered, washed with water and air dried to yield $2.1 \mathrm{~g}(90 \%)$ of the product and recrystallization with ethanol was done. The melting point 120-121 ${ }^{\circ} \mathrm{C}$ was observed [30].

\section{Cannizzaro reaction of 2-chlorobenzaldehyde}

This reaction demonstrates disproportionation, oxidation-reduction as well hydride shift-a process very important in many biological reactions and the conventional procedure involves the use of organic solvents while the underlying reaction procedure involves use of water for reaction work up, minimising the environmental pollution.

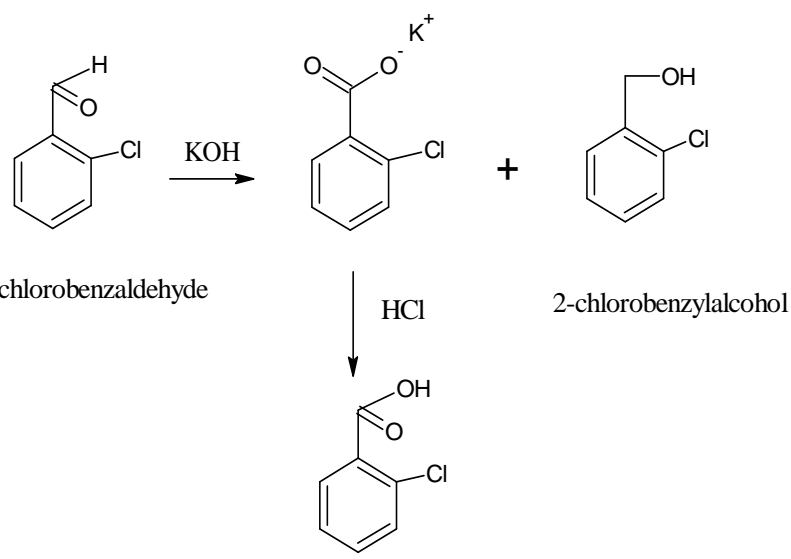

2-chlorobenzoic acid

(Scheme 9) 2-chlorobenzaldehyde $\left(1.78^{*} 10^{-3} \mathrm{~mol}, 2 \mathrm{ml}\right)$ and potassium hydroxide $\left(26.7^{*} 10^{-3} \mathrm{~mol}, 1.5 \mathrm{gm}\right)$ were grounded in the pestle mortar for 30 min (progress of reaction checked through thin layer chromatography, Scheme 9). Thick paste so obtained was filtered by using water. Solid 2-chlorobenzylalcohol, retained on the filter paper was washed with water and dried. The filtrate which contained potassium 2-chlorobenzoate was acidified, and the precipitates were filtered and dried to give 2-chlorobenzioc acid in $85 \%$ yield [31].

\section{Use of catalytical reagents}

Catalytic reagents are considered to be superior to stoichiometric reagents and has been widely applied in the pharmaceutical/ chemical industries, with the goal to curtail huge amounts of waste that is produced by the use of stoichiometric inorganic reagents. So, now a day heterogeneous, homogeneous, organocatalysts and, enzymes are used. The latter are predominantly effective at catalysing highly selective processes with complex substrates under mild reaction conditions and, hence, are finding broad utility in the pharmaceutical and allied industries helping in transition from chemical industry based on non-renewable fossil resources to a more sustainable bio-based economy.

Traditional mineral acids and Lewis acids have been replaced by solid acids as safer alternatives. Clays, zeolites, metal oxides, and ion-exchange resins are usually engaged as a catalytic agent in research labs and industry as they are stable, easy to store and handle and do not produce hazardous waste.

\section{Synthesis of 7-hydroxy-4-methylcoumarin from resorcinol}

Conventional procedure of condensation of resorcinol with ethyl acetoacetate involves conc. $\mathrm{H}_{2} \mathrm{SO}_{4}$ used as dehydrating reagent which in following procedure has been replaced by solid acid catalyst K10 montmorrilonite clay. Moreover reaction is done in the solid state avoiding use of solvents.

Resorcinol (1.1 g, $0.01 \mathrm{~mol}$ ) was dissolved completely in ethyl acetoacetate $(1.35 \mathrm{~g}, 0.01 \mathrm{~mol})$ in a $50 \mathrm{ml}$ dry flask to which $\mathrm{K} 10$ montmorillonite clay (1.5 g) was added and mixed thoroughly using a glass rod (Scheme 10). The reaction mixture finally appeared as a paste, was placed on a hot water bath for 3-4 h. After cooling the reaction mixture, 7-hydroxy-4-methylcoumarin was extracted with ether. The clay was removed by filtration through filter paper (Whatmann 4). After evaporation of filtrate, the product was obtained as a white solid in $85 \%$ Yield (1.5 g) having a melting point at $180^{\circ} \mathrm{C}[32]$.<smiles>CCOC(=O)COC(C)=[Te]</smiles>

Resorcinol
Ethyl acetoacetate

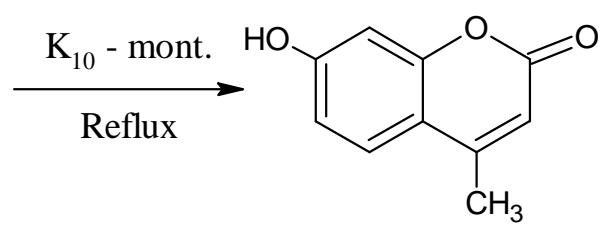

7-hydroxy-4-methyl coumarin

(Scheme 10) 


\section{Atom economy}

The primary goal of green chemistry is to minimise or preferably to eliminate the waste in the synthesis of chemicals/allied products which have resulted into a paradigm shift in the concept of efficiency in organic synthesis i.e. from chemical yield to minimization of waste. The principle of atom economy is based on the simple concept "All reactants are incorporated in the final desired product" [33]. Percentage yield of the reaction measures the reaction's efficiency. When all the reactants are incorporated in the product, the efficiency becomes $100 \%$ as explained by under mentioned reaction.

\section{Benzil benzilic acid rearrangement}

The conventional procedure involves refluxing of benzil in ethanol. Removal of ethanol as the solvent and its removal require time and energy. Moreover, expensive potassium hydroxide $(\mathrm{KOH})$ as base, decolourising carbon and celite for purification are used. The "green" solvent free and atom-efficient procedure uses only solid $\mathrm{NaOH}$, water and conc. $\mathrm{HCl}$ to accomplish the same reaction in a shorter amount of time with similar yields is mentioned in Scheme 11.

Benzil (1 g, $0.004 \mathrm{~mol}$ ) was thoroughly grounded with solid $\mathrm{NaOH}$ or $\mathrm{KOH}(1 \mathrm{~g})$ using a dry pestle mortar to form a fine powder (Scheme 11). This material was subsequently taken in a dry conical flask fitted with guard tube and heated on a boiling water-bath for $20 \mathrm{~min}$. The mixture was cooled to room temperature, dissolved in minimum amount of water. The solid unreacted benzil was removed by filtration. The solution was acidified with conc. $\mathrm{HCl}$ with thorough cooling in ice to precipitate benzilic acid which was filtered, washed with cold water and crystallised from hot water having a melting point $149-151^{\circ} \mathrm{C}$ and in $80 \%$ yield (0.86 g) [19].<smiles>O=C(C(=O)c1ccccc1)c1ccccc1</smiles>

Benzil<smiles>O=C(O)C(O)(c1ccccc1)c1ccccc1</smiles>

Benzilic Acid

(Scheme 11)

\section{Design for energy efficiency}

To reduce environmental and economic impacts, energy requirements should be minimized. Organic synthesis should be accomplished at ambient temperature and pressure, but chemists do not bother about temperature and pressure.

They just follow a procedure to get a reaction to go to completion to separate the desired product at higher a yield as possible. From the chemist's perspective, energy consideration is irrelevant.

On the other hand, Energy is a key issue for the $21^{\text {st }}$ century. A majority of the energy that is produced is based on fossil fuels which are depleting day by day. So energy considerations become of paramount importance. Reactions themselves are rarely where a majority of energy is used; most of it is used in solvent removal, or to isolate the desired product, or to remove impurities.

Now chemist's attention is drawn to the fact that energy minimization can be attained by following different procedures, either use of microwave or ultrasonic radiations or by decreasing the time of the reaction by adopting solventless conditions or use of catalysts.

\section{Minimum use of energy for reactions}

\section{Synthesis of dihydropyrimidinone}

Dihydropyrimidinone derivatives are of paramount importance because of their promising biological activities as calcium channel blockers, antihypertensive agents and anticancer drugs.

The conventional procedure requires old Biginelli's reaction involving acid catalyzed three-component condensation of 1, 3dicarbonyl compound, aldehyde and urea, solvent workup and long reaction time (18 h). Thus, as a part of green synthesis, Ranu et al., (2002) have discovered that Biginelli's reaction proceeds very efficiently by stirring a mixture of neat reactants at $90{ }^{\circ} \mathrm{C}$ for an hour, requiring no solvent and catalyst, and producing dihydropyrimidinones in high yields. Green solventless procedure is given below [34].

A mixture of benzaldehyde (1.1 g, $0.01 \mathrm{~mol})$, ethyl acetoacetate $(1.3 \mathrm{~g}, 0.01 \mathrm{~mol})$ and urea $(0.7 \mathrm{~g}, 0.01 \mathrm{~mol})$, taken in a round bottom flask was shaken by hand for swirling the flask for two minutes (Scheme 12). The reaction mixture was then heated in a water bath at $90{ }^{\circ} \mathrm{C}$ for one hour. A solid started depositing in the flask and after one hour, the flask is full of solid. The solid was removed out carefully with the help of spatula from the flask. The yellow solid so obtained, was washed with cold water (1 ml) and recrystallized from rectified spirit to give a colorless solid in $79 \%$ yield ( 2 g, m. p. $\left.201-202^{\circ} \mathrm{C}\right)$.

\section{Synthesis of laurolactam from cyclododecanone}

Cyclododecanone acts as a precursor for laurolactam which is used for the production of polyamide-12 (nylon-12) [35], synthesis of perfumes, such as muscone [36], pesticides [37] and pigments [38].

An efficient, simple and green procedure for Beckmann rearrangement, the conversion of a ketone via its oxime to the amide, is reported in Scheme $13[39,40]$.

\section{a) Conversion to cyclododecanone oxime, 2}

In a round bottom flask, 1.5 grams $\left(8^{*} 10^{-3} \mathrm{~mol}\right)$ of cyclododecanone (1) in about $8 \mathrm{ml}$ of ethanol (95\%) was dissolved and 0.6 grams $\left(8^{*} 10^{-3} \mathrm{~mol}\right)$ of hydroxylamine hydrochloride ( $97 \%$ pure), along with $25 \mathrm{ml}$ of deionized water was added to it. After this $15 \mathrm{ml}$ of a $10 \%$ aqueous solution of $\mathrm{NaOH}$ (by weight) was added (Scheme 13). The solution was refluxed at $100{ }^{\circ} \mathrm{C}$ on a heating mantle. Completion of the reaction was marked by the formation of large crystals which float on the surface of the reaction mixture, usually after $35 \mathrm{~min}$. The mixture was chilled in an ice/water bath, and the crystals were recovered by filtration. The crystals were allowed to dry on filter paper. The melting point of the product 2 was $132-133^{\circ} \mathrm{C}$ and yield $95 \%$. 


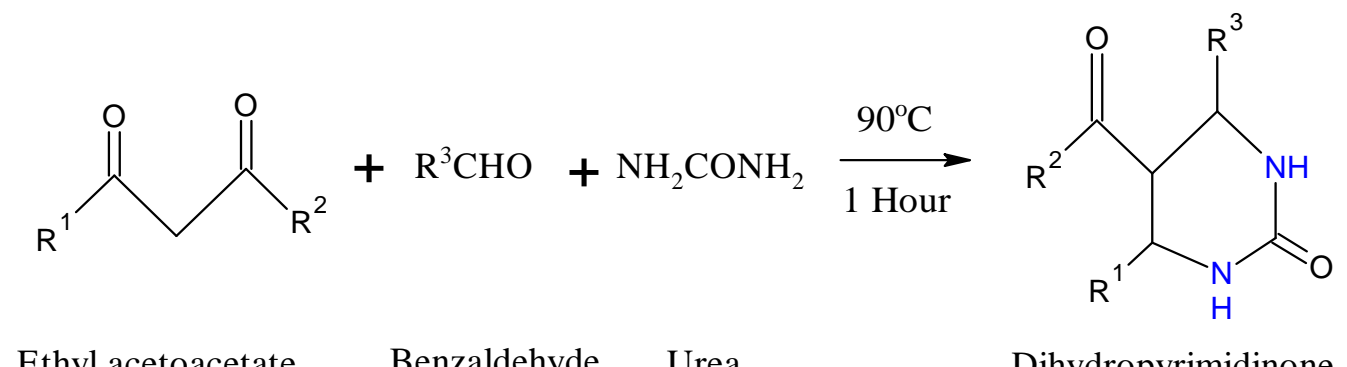

$$
\mathrm{R}^{1}=\mathrm{CH}_{3} \quad \mathrm{R}^{2}=\mathrm{C}_{2} \mathrm{H}_{5} \quad \mathrm{R}^{3}=\mathrm{C}_{6} \mathrm{H}_{5}
$$

(Scheme 12)

\section{b) Conversion to laurolactam 3}

To a round bottom flask, the recrystallized cyclododecanone oxime was added along $12 \mathrm{ml}$ of the acetonitrile solution containing $8.0 \mathrm{mg}$ of cyanuric chloride $\left(0.04^{*} 10^{-3} \mathrm{~mol}\right)$ and $11.5 \mathrm{mg}$ of anhydrous zinc chloride $\left(0.08^{*} 10^{-3} \mathrm{~mol}\right)$ (Scheme 13$)$. The solution was refluxed $(82$ ${ }^{\circ} \mathrm{C}$ ) for about $60 \mathrm{~min}$. The completion of the reaction was monitored by using thin-layer chromatography (methyl tert-butyl ether and petroleum ether, 1:1). After the completion of the reaction, the mixture was quenched with $20 \mathrm{ml}$ of a saturated aqueous solution of sodium bicarbonate $\left(\mathrm{NaHCO}_{3}\right)$. The product was extracted by using three portions ( $15 \mathrm{ml}$ each) of ethyl acetate.

After the separation, ethyl acetate layer was dried over anhydrous magnesium sulfate $(0.5 \mathrm{~g})$ by stirring for about ten minutes. Once dried, the magnesium sulfate was removed by filtration from the solution using a buchner funnel and the solution was concentrated under vacuum to give a product having a melting point $148-149^{\circ} \mathrm{C}$ and yield $90 \%$.

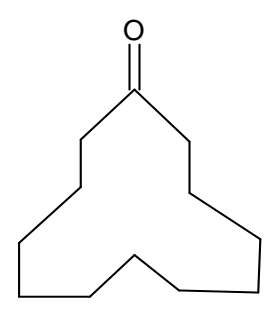

1 Cyclododecanone

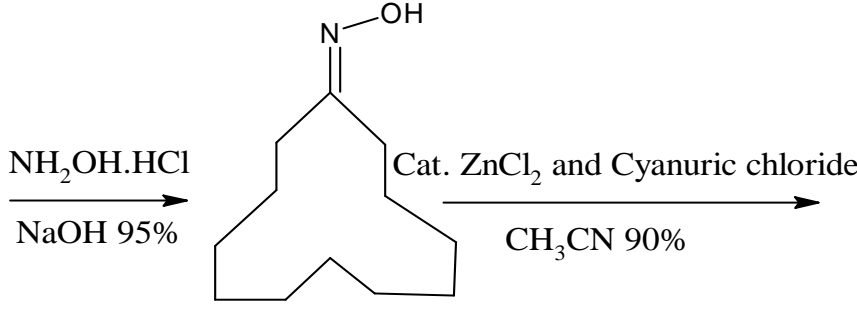

2 Cyclododecanone oxime

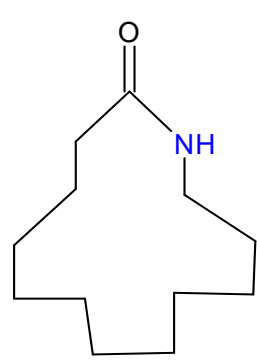

3 Laurolactam

(Scheme 13)

\section{Benzoylation of anthranilic acid in the presence of base}

In a round bottom flask, benzoyl chloride, $1\left(0.349 \mathrm{ml}, 3^{*} 10^{-3}\right.$ $\mathrm{mol})$, anthranilic acid, $2\left(0.411 \mathrm{~g}, 3^{*} 10^{-3} \mathrm{~mol}\right)$ and triethylamine $\left(0.460 \mathrm{ml}, 3.3^{*} 10^{-3} \mathrm{~mol}\right)$ in chloroform $(10 \mathrm{ml})$ were mixed (Scheme 14) and the mixture was stirred at room temperature for $2 \mathrm{~h}$. A solution of cyanuric chloride $\left(0.553 \mathrm{~g}, 3^{*} 10^{-3} \mathrm{~mol}\right)$ in dimethylformamide $(5 \mathrm{ml})$ was prepared and was added to the stirred reaction mixture. After $4 \mathrm{~h}$, the solvent was evaporated using vacuum and the residue was transferred into distilled water $(20 \mathrm{ml})$ and ice and filtered. The solids obtained was washed with a saturated solution of $\mathrm{NaHCO}_{3}(10 \mathrm{ml}$, two times) and subsequently with distilled water (two times, $25 \mathrm{ml}$ each). The white precipitates were recrystallized from a 1:1 diethyl ether/ethanol mixture to give the fine needle-shaped crystals of 2-phenyl-4H-3, 1benzoxazin-4-one (3) (0.578 g, yield: $86 \%$, m. p: $\left.123-124^{\circ} \mathrm{C}\right)$ [41].

\section{Synthesis of 2-arylbenzothiazoles (schiff's base)}

Schiff's base is an important class of compound which can be used for the determination of metals such as iron in pharmaceutical samples spectrophotometrically [42], as well as may show diverse pharmacological activities [43].

\section{Reaction of 2-aminothiophenol and aromatic aldehydes}

The conventional method of preparation of schiff bases involve either refluxing of aldehyde and amine in solvents like benzene or stirring at room temperature in chlorinated solvents.

A one-pot synthesis of 2-arylbenzothiazoles from the reaction of 2aminothiophenol and aromatic aldehydes catalyzed by cerium (IV) ammonium nitrate (CAN) is reported.

The reaction of equimolar amounts of 1 (2-aminothiophenol) and 2 (aromatic aldehydes) in methanol $(\mathrm{MeOH})$ in the presence of CAN resulted into corresponding 2-arylbenzothiazoles 4 in good yields $(75-89 \%)$ via the intermediate formation of schiff's bases 3 [44].

To a mixture of $1\left(0.626 \mathrm{~g}, 5^{*} 10^{-3} \mathrm{~mol}\right)$ and $2\left(5^{*} 10^{-3} \mathrm{~mol}\right)$ in methanol $(10 \mathrm{ml})$ was added with stirring $10 \%$ mol of cerium (IV) ammonium nitrate (CAN) (Scheme 15).

The reaction mixture was stirred at room temperature overnight. Brine solution was added to it and the solid formed was filtered, dried and recrystallized from ethanol to afford compounds $4 a-h$ (table 1). 


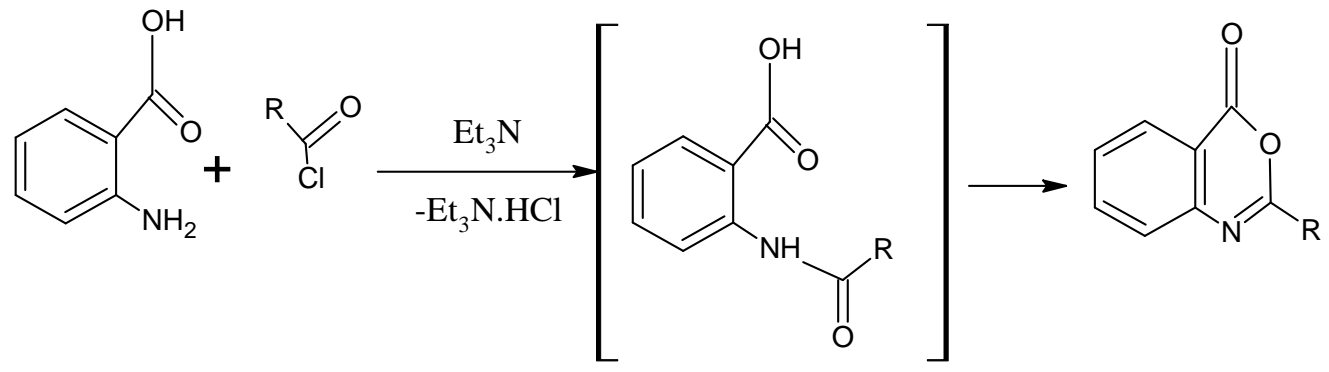

Anthranilic acid
$2\left(\mathrm{R}=\mathrm{C}_{6} \mathrm{H}_{5}\right)$

Benzoyl Chloride
2-phenyl-4H-3,1-benoxazin-4-one

(Scheme 14)

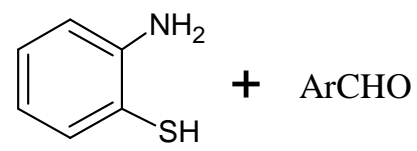

1

2-aminothiopheno

$2 \mathrm{a}-\mathrm{h}$

Aromatic aldehyde

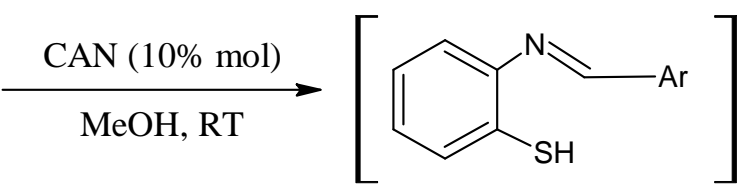

3<smiles></smiles><smiles>Brc1nc2ccccc2s1</smiles>

$4 a-h$

2-arylbenzothiazoles

(Scheme 15)

Table 1: Showing \% yield and melting point of the products obtained via scheme 15

\begin{tabular}{|c|c|c|c|}
\hline Compound & Name of the product & $\%$ Yield & Melting Point $\left({ }^{\circ} \mathrm{C}\right)$ \\
\hline $4 \mathrm{a}$ & 2-Phenyl-1,3-benzothiazole & 75 & $112-113$ \\
\hline $4 b$ & 2-(4-Methoxyphenyl)-1,3-benzothiazole & 78 & $126-128$ \\
\hline $4 c$ & 2-(3,4-Dimethoxyphenyl)-1,3-benzothiazole & 77 & $130-132$ \\
\hline $4 d$ & 2-(3-Nitrophenyl)-1,3-benzothiazole & 88 & $184-186$ \\
\hline $4 \mathrm{e}$ & 2-(2-Chlorophenyl)-1,3-benzothiazole & 89 & $71-73$ \\
\hline $4 \mathrm{f}$ & 2-(2-Methoxyphenyl)-1,3-benzothiazole & 80 & $102-103$ \\
\hline $4 g$ & 2-(4-Nitrophenyl)-1,3-benzothiazole & 87 & $224-225$ \\
\hline $4 \mathrm{~h}$ & 2-Thienyl-1,3-benzothiazole & 79 & $97-99$ \\
\hline
\end{tabular}

\section{Microwave assisted synthesis}

Microwave induced reactions are considered to be fast, show reduction in unwanted side reactions, economical, efficient, produces high yield, easy scale-up, reproducibility, purity of the product and show reduced environmental heat loss [45]. In conventional heating, heat is transferred through conduction, convection or radiation but in microwave heating, electromagnetic energy is transformed into heat through ionic conduction and the friction due to the rapid reorientation of the dipoles. 
The higher dipole moment results in to vigorous oscillations in the microwave field, subsequently more heating which is fast has no inertia, and is in-situ without heating the environments. Usually, polar solvents like water, acids, amides and alcohols are engaged for microwave reactions.

Microwave reactions in the solid state [46] are usually employed in contrast to conventional reactions conducted in liquid solutions which result into dramatic reduction in reaction time (often from hours to minutes). Solvent-free microwave assisted reactions [47] give an opportunity to work with open vessels, which reduce the risk of high pressure and increase the probability for scale up of such reactions.

The important practical applications of microwave-assisted solvent free syntheses have been corroborated in underlying trans-formations:
Microwave-stimulated synthesis of ethylbenzene i.e. WolfKishner reduction

The conventional procedure involves refluxing at $75{ }^{\circ} \mathrm{C}$ for one and half hour. $10 \mathrm{ml}$ acetophenone $(0.29 \mathrm{~mol}), 30 \mathrm{ml}$ diethylene glycol $(0.085 \mathrm{~mol}), 9 \mathrm{ml}$ hydrazine hydrate $(0.54 \mathrm{~mol})$ and $\mathrm{KOH}$ pellets under microwave irradiation in $5 \mathrm{~min}$ at $110{ }^{\circ} \mathrm{C}$ temperature and 160-watt power resulted into ethyl benzene (Scheme 16). The reaction mixture was transferred to a separating funnel and lower aqueous layer was discarded. The aqueous layer was extracted with $10 \mathrm{ml}$ ether. Excess ether was removed by heating on a water bath. The resultant mixture was dried with anhydrous magnesium sulphate $\left(\mathrm{MgSO}_{4}\right)$ and a yellowish solution with gasoline like smell was obtained $135-139^{\circ} \mathrm{C}$ in $74 \%$ yield [48].<smiles>CC(=O)c1ccccc1</smiles>

Acetophenone<smiles>OCCOCCO</smiles>

Diethylene Glycol $+\mathrm{NH}_{2} \mathrm{NH}_{2} \cdot \mathrm{H}_{2} \mathrm{O}$

Hydrazine Hydrate

\section{$70-75^{\circ} \mathrm{C}, 1.5$ Hour}

$110^{\circ} \mathrm{C}, 5 \mathrm{~min} ., 160 \mathrm{~W}$, Microwave

\section{Ethyl Benzene}

(Scheme 16)

\section{Schiff bases of 3, 4, 5-trimethoxybenzaldehyde and p-toluidine}

A mixture of p-toluidine $\left(0.107 \mathrm{~g}, 1^{*} 10^{-3} \mathrm{~mol}\right), 3,4,5$-trimethoxybenzaldehyde $\left(0.196 \mathrm{~g}, 1 * 10^{-3} \mathrm{~mol}\right)$, neutral alumina $(1 \mathrm{~g})$ and dichloromethane $(2 \mathrm{ml})$ was taken in a conical flask and was irradiated for 4 min (output power at 20\%) into the microwave oven (Scheme 17). After cooling, the solid was recrystallized from ethyl acetate $/$ petroleum ether to offer $0.242 \mathrm{~g}\left(85 \%, \mathrm{~m} . \mathrm{p} .=91-93^{\circ} \mathrm{C}\right)$ of the product [(E)-4-methyl-N-(3,4,5-trimethoxybenzylidene)] benzenamine as white lamellar crystals [49].<smiles>COc1cc(C=O)cc(OC)c1OC</smiles>

3,4,5-trimethoxy

benzaldehyde<smiles>Cc1ccc(N)cc1</smiles>

p-toluidine<smiles>COc1cc(/C=N/c2ccc(C)cc2)cc(OC)c1OC</smiles>

Schiff base

(Scheme 17)<smiles>O=Cc1ccccc1</smiles><smiles>Nc1ccc(P)cc1</smiles>
2<smiles>[R]1cccc(N=Cc2ccccc2)c1</smiles>

3

i (a) Conventional method: Ethanol/ acetic acid, reflux, 1.0-2.0 hours

i (b) Microwave method: Acetic acid, mw, 2.0-3.0 mins.

(Scheme 18)

\section{Synthesis of Schiff bases}

The synthesis of Schiff bases 3a-f was accomplished by the reaction of aromatic aldehydes $\left(1,10^{*} 10^{-3} \mathrm{~mol}\right)$ and different aromatic amines $\left(2,10^{*} 10^{-3} \mathrm{~mol}\right)$ along with the catalytic amount of glacial acetic acid under microwave radiations (Scheme 18, table 2). The conventional method required about $1.0-2.0 \mathrm{~h}$, while microwave irradiation method required only $2.0-3.0 \mathrm{~min}$ [50]. 
Table 2: Showing the melting point and \% yield of various schiff's bases

\begin{tabular}{llll}
\hline Compound No. & $\mathbf{R}^{\mathbf{1}}$ & $\mathbf{R}^{\mathbf{2}}$ & M. P. $\left.{ }^{\circ} \mathbf{C}\right)$ \\
\hline 3a & $4-\mathrm{OCH}_{3}$ & $4-\mathrm{Br}$ & $154-156$ \\
3b & $4-\mathrm{OCH}_{3}$ & $4-\mathrm{F}$ & $163-164$ \\
3c & $4-\mathrm{F}$ & $4-\mathrm{F}$ & $178-180$ \\
3d & $4-\mathrm{OH}$ & $3-\mathrm{Cl}$ & $172-174$ \\
3e & $4-\mathrm{OCH} \mathrm{CH}_{3}$ & $3-\mathrm{Cl}$ & $158-160$ \\
3f & $4-\mathrm{F}$ & $3-\mathrm{Cl}$ & $162-164$ \\
\hline
\end{tabular}

\section{Synthesis of Hantzsch dihydropyridines}

In a typical general procedure, a mixture of 1.0 molar equivalent aldehyde, 1.3 molar equivalent ammonium formate, and 2.2 molar equivalent ethyl acetoacetate in a flask (Scheme 19) fitted with a calcium chloride drying tube was irradiated in a microwave oven
(2450 MHz, $300 \mathrm{~W}$, Brand BPL, India) for the stipulated period of time having the installment of 15 seconds each and intermittent cooling. The reaction mixture was cooled to room temperature and thoroughly mixed with crushed ice. The precipitated solid was filtered, washed with water and dried. Recrystallization from aqueous alcohol yielded the pure product dihydropyridines (table 3) [51].

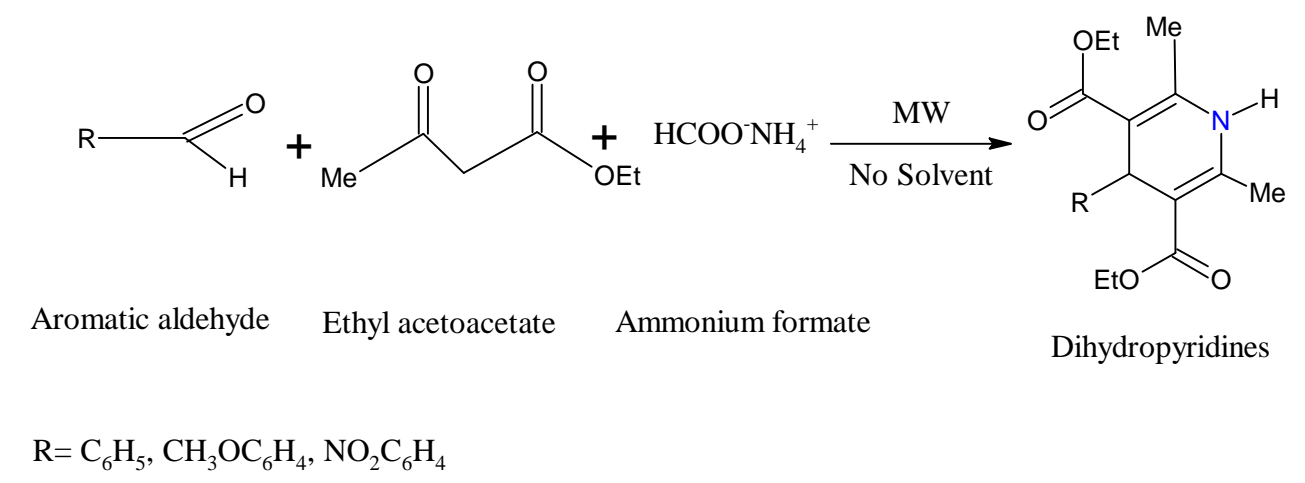

(Scheme 19)

Table 3: Ammonium formate-mediated solvent-free synthesis of dihydropyridines

\begin{tabular}{|c|c|c|c|}
\hline Aldehyde & Time(min) & $\%$ Yield & M. P. $\left({ }^{\circ} \mathrm{C}\right)$ \\
\hline Benzaldehyde & 3 & 78 & 156 \\
\hline p-Methoxybenzaldehyde & 3 & 90 & 140 \\
\hline p-Nitrobenzaldehyde & 3 & 91 & 124 \\
\hline
\end{tabular}

\section{Knoevenagel reaction}

p-anisaldehyde $\left(1.32 \mathrm{~g}, 10^{*} 10^{-3} \mathrm{~mol}\right)$, ethyl cyanoacetate $(1.13 \mathrm{~g}$, $\left.10^{*} 10^{-3} \mathrm{~mol}\right)$ and ammonium formate $\left(630 \mathrm{mg}, 10^{*} 10^{-3} \mathrm{~mol}\right)$ were mixed in a round-bottomed flask fitted with guard tube and placed on a bed of alumina taken in a beaker (Scheme 20) and was subjected to microwave irradiation for 90 seconds (with an installment of 30 seconds each at a power level of 300 watts followed by intermittent cooling). After completion of the reaction, the mixture was cooled to room temperature, and crushed ice $(20 \mathrm{~g})$ was added. The solid product, which precipitated in a granular form, was filtered, washed well with water and dried to give ethyl 2cyano-3-(4'-methoxyphenyl)-propionate (1.84 g, 80\%).

Recrystallization from ethyl acetate-petroleum ether $\left(60-80{ }^{\circ} \mathrm{C}\right)$ resulted in $80 \%$ yield $(1.8 \mathrm{~g})$ of product having $\mathrm{m}$. p. $88^{\circ} \mathrm{C}$ [52].<smiles>COc1ccc(C=O)cc1</smiles>

p-Anisaldehyde

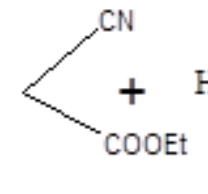

E thyl cyanoacetate Ammonium formate

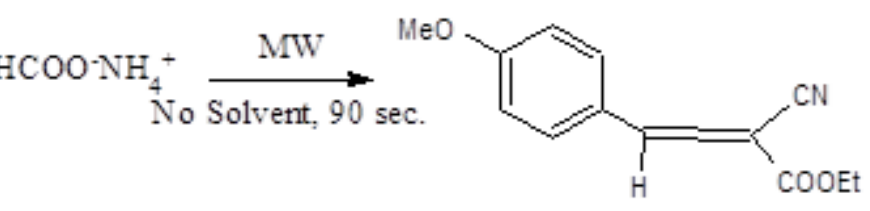

2-cyano 3-(4'-methoxyphenyi)ethyl propionate

(Scheme 20)

\section{Synthesis of pyrimidine derivatives}

Synthesis of pyrimidine derivatives can be accomplished by using microwave, mortal-pastle method and by the use of green solvents for the synthesis. 4-(4-Hydroxyphenyl)-6-methyl-2-oxo-1,2,3,4-tetrahydropyrimidine-5-carboxylic acid ethyl ester was prepared following a general Scheme 21 as stated below. The various experimental routes followed for the synthesis is as given below [53]. 


\section{Method A (microwave method)}

4-hydroxybenzaldehye $\left(0.122 \mathrm{~g}, 1^{*} 10^{-3} \mathrm{~mol}\right)$, ethyl acetoacetate $\left(0.127 \mathrm{ml}, 1^{*} 10^{-3} \mathrm{~mol}\right)$ and urea $\left(0.132 \mathrm{gm}, 2^{*} 10^{-3} \mathrm{~mol}\right)$ was taken in a conical flask, ethanol $(5 \mathrm{ml})$ as a solvent and p-toluene sulfonic acid (p-TSA, $0.034 \mathrm{~g}, 2 * 10^{-3} \mathrm{~mol}$ ) were added simultaneously to the above mixture. The mixture was irradiated for $3 \mathrm{~min}(30$-second interval at 20 power level). After completion of the reaction, the reaction mass was poured on ice and the precipitated solid was filtered, washed with water, oven dried and the crude product was crystallised in water and glacial acetic acid.

\section{Method B (By using pastle mortar)}

4-Hydroxybenzaldehye $\left(0.122 \mathrm{~g}, 1 * 10^{-3} \mathrm{~mol}\right)$, ethyl acetoacetate $\left(0.127 \mathrm{ml}, 1^{*} 10^{-3} \mathrm{~mol}\right)$ and urea $\left(0.132 \mathrm{~g}, 2^{*} 10^{-3} \mathrm{~mol}\right)$ were taken in a flat bottom flask. A small amount of water as a solvent and p-TSA $\left(0.034 \mathrm{gm}, 2^{*} 10^{-3} \mathrm{~mol}\right)$ were added simultaneously to the above mixture and mixture was stirred at room temperature for half an hour. After completion of the reaction, solid which separated was filtered, washed with water, dried in an oven and the crude product crystallized in water and glacial acetic acid mixture.

\section{Method C (Involving use of green solvent)}

4-Hydroxybenzaldehye $\left(0.122 \mathrm{~g}, 1 * 10^{-3} \mathrm{~mol}\right)$, ethyl acetoacetate $\left(0.127 \mathrm{ml}, 1^{*} 10^{-3} \mathrm{~mol}\right)$, urea $\left(0.132 \mathrm{~g}, 2^{*} 10^{-3} \mathrm{~mol}\right)$ and $\mathrm{p}$-TSA (ptoluene sulphonic acid) $\left(0.034 \mathrm{gm}, 2 * 10^{-3} \mathrm{~mol}\right)$ were taken in mortar and pestle, grounded for 4-5 min. This syrupy reaction mixture solidified within $15 \mathrm{~min}$. The solid was separated, filtered, washed with cold water and the crude product crystallized in a mixture of water and glacial acetic acid.<smiles>CCOC(=O)CC(C)=O</smiles>

4-Hydroxy benzaldehyde Urea

ethyl4-(4-hydroxyphenyl)-6-meth yl-2-oxo-1,2,3,4-tetrahydropyrimi dine-5-carboxylate

(Scheme 21)

The specified methods as mentioned above for synthesis are more convenient, safe and give higher yield (80-96\%) than traditional method
(71\%), take shorter reaction time (3-30 min) (table 4) and can be performed under milder conditions, without generation of pollution.

Table 4: Showing \% yield and melting point of ethyl 4-(4-hydroxyphenyl)-6-methyl-2-oxo-1,2,3,4-tetrahydropyrimidine-5-carboxylate by different green techniques

\begin{tabular}{llll}
\hline Method & Time taken & \% Yield & Melting point ( $\left.{ }^{\circ} \mathbf{C}\right)$ \\
\hline A & $3 \mathrm{~min}$ & 96 & 236 \\
B & $30 \mathrm{~min}$ & 80 & 238 \\
C & $4-5 \mathrm{~min}$ & 90 & 236 \\
\hline
\end{tabular}

Synthesis of 1-[1-(naphthalene-2-yl) ethylidene] hydrazine from 1-(naphthalene-2-yl) ethanone

$0.1 \mathrm{~mol}(17.1 \mathrm{~g})$ of 2-acetylnaphthalene was dissolved in $20 \mathrm{ml}$ of ethanol in a $250 \mathrm{ml}$ conical flask, and $0.1 \mathrm{~mol}(4.9 \mathrm{ml})$ of hydrazine hydrate (99\%) was added dropwise along with 4-5 drops of glacial acetic acid (Scheme 22). The flask was kept in a microwave oven for the duration of 3-5 $\mathrm{min}$ at $450 \mathrm{~W}$.

The progress of the reaction was examined by thin layer chromatography using n-hexane: ethylacetate $(6: 4)$ as a solvent. The reaction mixture was cooled and poured into ice cold water. Thus, the solid obtained was filtered, washed with $5 \% \mathrm{NaHCO}_{3}$ solution, dried and recrystallized from ethanol yielding product having a melting point $116-118^{\circ} \mathrm{C}[54]$.

\section{Synthesis of 2-phenylbenzothiazoles}

A mixture of benzaldehyde $\left(1.0 \mathrm{~g}, 10^{*} 10^{-3} \mathrm{~mol}\right)$ and 2-aminothiophenol $\left(1.25 \mathrm{~g}, 10^{*} 10^{-3} \mathrm{~mol}\right)$ was heated in a microwave oven $(10 \%$ power, $120 \mathrm{~W})$ in the presence of ionic liquid, 1-pentyl, 3methyl imidazolium bromide (pmlm Br, $500 \mathrm{mg}$ ) for $3 \mathrm{~min}$ (Scheme 23). After cooling the reaction mixture was extracted with ether and the ether extract was evaporated to give the crude product which was recrystallized using ethanol-water $(4: 1)$ to give a white solid having a melting point $112-115{ }^{\circ} \mathrm{C}$ in $90 \%$ (1.9 g) yield. This ionic liquid, [pmIm] Br works here as a catalyst as well as the reaction medium, without any involvement of solvent and the reaction is also atom efficient [55].

\section{Preparation of ionic liquid, [pmlm] Br}

$\mathrm{N}$-Methyl imidazole $\left(1.2 \mathrm{~g}, 15^{*} 10^{-3} \mathrm{~mol}\right)$ and n-pentyl bromide $(2.71$ g, $\left.18^{*} 10^{-3} \mathrm{~mol}\right)$, taken in a small round bottom flask fitted with a guard tube (Scheme 24), were heated in water bath at $80{ }^{\circ} \mathrm{C}$ for about one hour. A clear yellow viscous liquid which was formed, cooled and washed with a small amount of ether $(1 \mathrm{ml})$ twice to remove any unreacted bromide and remaining viscous liquid was dried by a vacuum pump to yield-3.42 g (88\%) of 1-pentyl, 3-methyl imidazolium bromide (pmlmBr).

\section{Synthesis of 2-hyroxydibenzoylmethanes}

A mixture of substituted 2-hydroxyacetophenone $\left(2^{*} 10^{-3} \mathrm{~mol}\right)$, aroyl chloride $\left(2 * 10^{-3} \mathrm{~mol}\right)$ and potassium carbonate $\left(10^{*} 10^{-3}\right.$ mol) homogenised by the addition of 8-10 drops of water was subjected to microwave irradiation for $30(5 \times 6)$ seconds (Scheme 25, table 5).

The reaction progress was checked by thin layer chromatography. The reaction mixture was diluted with ice cold water, acidified with conc. $\mathrm{HCl}$ (pH 5.5-6.0). The solid obtained was filtered, washed with water and recrystallized from aqueous ethanol to afford 2hydroxydibenzoylmethane [56]. 
<smiles>CC(=O)c1ccc2ccccc2c1</smiles>

(Scheme 22)
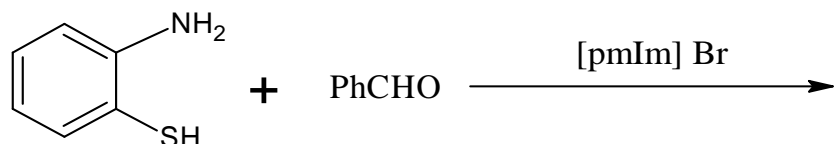<smiles>c1ccc(-c2nc3ccccc3s2)cc1</smiles>

\section{(Scheme 23)}<smiles>CCCCCBr</smiles><smiles>CCCCC[n+]1ccn(C)c1</smiles>

(Scheme 24)<smiles>[R]c1cc(O)c(C(C)=O)cc1[12F]</smiles>

Substituted 2hydroxy acetophenone<smiles>[Z8]c1ccc(C(=O)CC(=O)c2cc([R7])c([R7])cc2O)c([R])c1</smiles>

aroyl chloride<smiles>[R7]c1ccc(/C(O)=C/C(=O)c2ccc([R7])cc2O)c([R])c1</smiles>

2-hydroxydibenzoylmethanes

(Scheme 25)

Table 5: Showing \% yield and m. pt of 2-hydroxydibenzoylmethane

\begin{tabular}{llllll}
\hline $\mathbf{R}^{\mathbf{1}}$ & $\mathbf{R}^{\mathbf{2}}$ & $\mathbf{R}^{\mathbf{3}}$ & $\mathbf{R}^{\mathbf{4}}$ & \%Yield & M. P. $\left({ }^{\circ} \mathbf{C}\right)$ \\
\hline $\mathrm{H}$ & $\mathrm{H}$ & $\mathrm{H}$ & $\mathrm{H}$ & 80 & $117-118$ \\
$\mathrm{CH}_{3}$ & $\mathrm{H}$ & $\mathrm{H}$ & $\mathrm{H}$ & 85 & $80-82$ \\
$\mathrm{H}$ & $\mathrm{OCH}_{3}$ & $\mathrm{H}$ & $\mathrm{H}$ & 90 & $100-101$ \\
$\mathrm{H}$ & $\mathrm{H}$ & $\mathrm{H}$ & $\mathrm{OCH}_{3}$ & 95 & $109-110$ \\
\hline
\end{tabular}




\section{Synthesis of trifluoromethyl-containing tetrahydropyridines}

A mixture of 4, 4, 4-trifluoro-1-(4-methoxyphenyl) butane-1,3dione $1\left(5^{*} 10^{-3} \mathrm{~mol}\right)$, different aromatic aldehydes $2\left(5^{*} 10^{-3} \mathrm{~mol}\right)$ and urea $3\left(5^{*} 10^{-3} \mathrm{~mol}\right)$ was irradiated under microwave at the power of $600 \mathrm{~W}$ at $110-120^{\circ} \mathrm{C}$. (table 6, Scheme 26). After cooling, the solid was washed with cold water, filtered and dried under vacuum to yield the crude product which on recrystallization from hot ethanol provided the pure product [57].

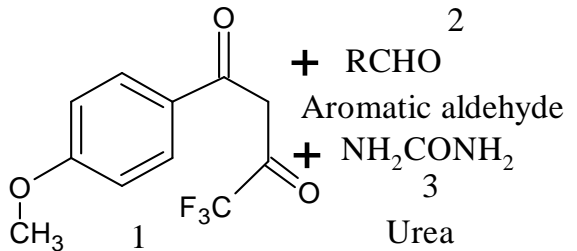

4,4,4-trifluoro-1-(4-methoxyphe nyl)butane-1,3-dione<smiles>[2H]C1([2H])NC(=O)N[C@](O)(C(F)(F)F)[C@@H]1C(=O)c1ccc(OC)cc1</smiles>

4 a-c , R= Aryl

Tetrahydropyrimidines

(Scheme 26)

Table 6: Trifluoro tetrahydropyridines along with yield and melting point

\begin{tabular}{|c|c|c|c|c|}
\hline Compound & $\mathbf{R}$ & Yield (\%) & M. P. $\left({ }^{\circ} \mathrm{C}\right)$ & Time (min) \\
\hline $4 \mathrm{a}$ & & 85 & $180-182$ & 1.5 \\
\hline $4 b$ & & 82 & $205-206$ & 2 \\
\hline $4 c$ & & 79 & $212-214$ & 1.5 \\
\hline
\end{tabular}

Montmorillonite $\mathrm{K}-10$ is a stable, inexpensive, strong, solid acid which is commercially available heterogeneous catalyst active under microwave which causes a reduction in solvent use. De Paolis et al., (2009) [58] have pronounced an environmentally friendly microwave-assisted solid acid-catalyzed synthesis of quinolines from anilines and cinnamaldehydes. The catalyst montmorillonite K-10 guarantees effective condensation, cyclisation and aromatization to the final product. In this one-pot process, the solvent-free cyclization and oxidation steps readily take place (Scheme 27). The yield of product was found to be $95 \%$ when reactant ratio: aniline $\left(1.5^{*} 10^{-3} \mathrm{~mol}\right)$ and cinnamaldehyde $\left(1 * 10^{-3} \mathrm{~mol}\right)$ were used.<smiles>[R]c1ccc([NH-])cc1[R]</smiles>

Aniline

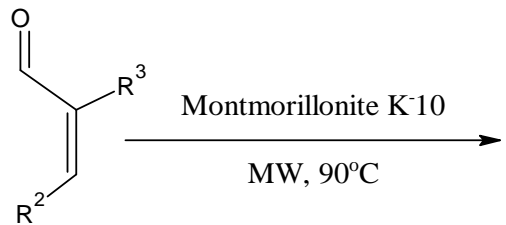

Cinnamaldehyde<smiles>[R]c1cc2cc([10B])c([R7])nc2cc1[3H]</smiles>

Quinoline

$\mathrm{R}, \mathrm{R}^{1}=\mathrm{H}$, alkyl, halogen; $\mathrm{R}^{2}=$ aryl; $\mathrm{R}^{3}=\mathrm{H}$, alkyl

(Scheme 27)

The same reaction has been reported to be slow under conventional heating, whereas dielectric heating not only improves reaction yields and but also show selectivity in just a few minutes.

\section{Microwave synthesis of aspirin}

Somenath Mitra et al. [59], carried out microwave-induced reactions. 18 $\mathrm{ml}$ of acetic anhydride $(0.19 \mathrm{~mol})$ was slowly mixed with 10 grams of salicylic acid ( $0.07 \mathrm{~mol})$ in a $250 \mathrm{ml}$ Erlenmeyer flask. 10 to 20 drops of $85 \%$ phosphoric acid was carefully added to the solution and mixed thoroughly. The mixture was heated under MW for one minute till all the salicylic acid was dissolved. After completion of the reaction, $20 \mathrm{ml}$ of distilled water was cautiously added to the mixture, and the solution was cooled on an ice bath until aspirin crystallized. The crystals were filtered using a Buchner filter and extracted using chilled water. The solid was 
oven dried at $100{ }^{\circ} \mathrm{C}$ for half an hour, weighed and the yield (95\%) was calculated with a melting temperature range of $128-132{ }^{\circ} \mathrm{C}$. The<smiles>CC(=O)OC(C)=O</smiles>

Acetic Anhydride<smiles>O=C(O)c1ccccc1O</smiles>

Salicylic acid microwave method of synthesis is not only energy efficient than the hotplate method but also gave higher yield (Scheme 28).<smiles>CC(=O)Oc1ccccc1C(=O)O</smiles>

Acetyl Salicylic Acid

Acetic acid

(Scheme 28)

Similarly, Fatemeh et al., (2007) [60] reported the innovative clean procedure for the synthesis of aspirin by 0-acetylation of salicylic acid in the presence of Preyssler type hetero polyacids at room temperature.

\section{Ultrasonic waves assisted synthesis}

Ultrasound is a relatively new technique of doing chemical reactions [61]. It has been used to enhance reaction rates in a large number of classical reactions. Some of these reactions which can be carried out in the labs are mentioned below.

\section{Synthesis of 1, 2-Cis diols from olefins}

In a typical experiment, styrene (208 $\mathrm{mg}, 2^{*} 10^{-3} \mathrm{~mol}$ ) was added to the finely powdered $\mathrm{KMnO}_{4}\left(474 \mathrm{mg}, 3^{*} 10^{-3} \mathrm{~mol}\right)$. To this mixture, tertiary butanol $(1 \mathrm{ml})$ was added which was followed by water $(15-20 \mathrm{ml})$ and the reaction mixture was irradiated by using Ultrasonic processor (Heat systems-Ultrasonics, Inc., W-380) (Scheme 29).

On completion of the reaction, as monitored by thin layer chromatography (hexane; Ethyl acetate, $4: 1 \mathrm{v} / \mathrm{v}$ ), the product was extracted into dichloromethane $(3 \times 15 \mathrm{ml})$, the combined organic extract was dried over anhydrous sodium sulfate and solvent was removed under vacuum giving product in $80 \%$ yield [62].
The simple procedure, the use of an inexpensive oxidizing agent, fast reaction and high yields of pure product formation when compared to existing practices makes this a very useful and attractive alternative to the conventional available procedures.

\section{Synthesis of azlactone}

Benzaldehyde $\left(2 * 10^{-3} \mathrm{~mol}\right)$, hippuric acid $\left(2.2^{*} 10^{-3} \mathrm{~mol}\right)$, acetic anhydride $\left(6.6^{*} 10^{-3} \mathrm{~mol}\right)$, and potash alum $\left[\mathrm{KAl}\left(\mathrm{SO}_{4}\right)_{2} .12 \mathrm{H}_{2} \mathrm{O}\right](10 \mathrm{~mol}$ $\%)$ mixture was irradiated under ultrasound irradiation at ambient temperature for $8 \mathrm{~min}$. The yellow solid which precipitated on the addition of $5 \mathrm{ml}$ of $95 \%$ ethyl alcohol, was filtered, washed with hot water and recrystallized with acetone/water to give azlactone in $96 \%$ yield and had a melting point $168-170^{\circ} \mathrm{C}$ (Scheme 30) [63].

\section{Synthesis of benzimidazole thio unsaturated nitriles (2) from 2 -} cyanothiomethyl benzimidazole, 1

To a mixture of 2-cyanothiomethylbenzimidazole, $1\left(10^{*} 10^{-3} \mathrm{~mol}\right)$, benzaldehyde $\left(10^{*} 10^{-3} \mathrm{~mol}\right)$ in water $(20 \mathrm{ml})$ was added under constant sonication parameters. The reaction progress was monitored by thin layer chromatography and after 10 minutes (Scheme 31), the reaction was found to be completed. The mixture was filtered and dried. Recrystallization of crude product was done from ethyl acetate to obtain product 2 in $98 \%$ yields having a melting point $192-194^{\circ} \mathrm{C}[64]$.<smiles>[13CH2]C=C[13CH3]</smiles>

Styrene

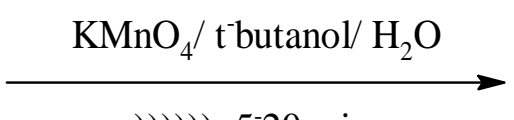

))))), 5-20 $\min$.<smiles>CC(C)C(O)CO</smiles>

cis-1-phenyl ethane, 1,2-diol

(Scheme 29)<smiles>CCCC1N=C(c2ccccc2)OC1=O</smiles> 
<smiles>N#CCSc1nc2ccccc2[nH]1</smiles>

1

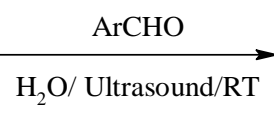

$\mathrm{Ar}=\mathrm{C}_{6} \mathrm{H}_{5}$

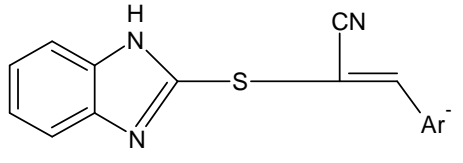

2

Benzimidazolylthiounsaturatednitriles

(Scheme 31)

\section{CONCLUSION}

Green chemistry is growing at a very fast pace and provides a pre-emptive avenue for the sustainable development for future science and technology which can be useful to the design of highly effectual, environmentally friendly synthetic practices/procedures to provide life-saving medicines and to quicken lead optimisation processes in drug discovery while minimising environmental degradation. It also offers enhanced chemical process economics, concomitant with a reduced environmental affliction. The eco-friendly advantages of the synthetic alternatives based on unconventional methods like microwave or ultrasound irradiation or the usage of eco-friendly solvents like water etc. are becoming progressively popular and may be adopted by the chemical/pharmaceutical industry to reduce or eliminate volatile organic solvents, thus averting pollution at source, to diminish the reaction time and elimination/minimization of side product formation. Thus there is a need to change or modify the conventional procedures as newer strategies to produce organic materials in a variety of media for their safer use may be advantageous by the use of green chemistry principles and these processes are to be taught to the science students at undergraduate levels. By learning these principles, students will develop the potential to assess the reaction conditions of a conventional reaction by focusing on solvents and reagents first, identify harmful materials or inefficient procedures, modify the process and test/evaluate the efficacy of the new procedure. Moreover, experiments set up according to green chemistry protocol can easily be conducted on lab benches i.e. it will reduce reliance on fume hoods and will improve the student's perception of chemistry.

\section{CONFLICT OF INTERESTS}

\section{Declared none}

\section{REFERENCES}

1. Clark JH. Chemistry goes green. Nat Chem 2009;1:12-3.

2. Reed SM, Hutchison JE. Green chemistry in the organic teaching laboratory: an environmentally benign synthesis of adipic acid. J Chem Educ 2000;77:1627-8.

3. Ahluwalia VK, Kidwai M. New trends in green chemistry. Springer, Berlin; 2004. p. 2-4.

4. Anastas PT, Warner JC. Green Chemistry: Theory and Practice. Oxf Univ Press: New York; 1998. p. 29-56.

5. Hjeresen DL, Schutt DL, Boese JM. Green chemistry and education. J Chem Educ 2000;77:1543-7.

6. Gribble GW. The diversity of naturally occurring organobromine compounds. Chem Soc Rev 1999;28:335.

7. Monograph on Green Chemistry. Laboratory Experiments. Green Chemistry Task Force Committee, DST, India; 2011. p. 1-79.

8. Schatz PF. Bromination of acetanilide. J Chem Educ 1996;73:26.

9. Gupta R, Lata. An economical and eco-friendly regioselective bromination of acetanilides using potassium bromide and ceric ammonium nitrate in polyethene glycol. Heterocyclic Lett 2012;2:297-300.

10. Halder J. An elegant and cost-effective method of aromatic bromination using sodium bromide and household bleach Rasayan J Chem 2012;5:183-5.
11. McKenzie LC, Huffman LM, Hutchison JE. The evolution of a green chemistry laboratory experiment: greener brominations of stilbene. J Chem Educ 2005;82:306.

12. Bose AK, Ganguly SN, Manhas MS, Rao S, Speck J, Pekelny U, et al. Microwave-promoted rapid nitration of phenolic compounds with calcium nitrate. Tetrahedron Lett 2006;47:1885-8.

13. Lampman PDL, Chriz GM. Introduction to organic lab technique. College Publishing, New York; 1982.

14. Andrew PD. Solvent-free reactivity in the undergraduate organic laboratory. Green Chem Lett Rev 2009;2:87-100.

15. Modarresi-Alam AR, Nasrollahzadeh M, Khamooshi F. Solventfree preparation of primary carbamates using silica sulfuric acid as an efficient reagent. ARKIVOC 2007;16:238-45.

16. Epps A, Barbas J, Mandouma G. Synthesis of substituted 2, 2'dinitrobiphenyls by a novel solvent-free high yielding ullmann coupling biarylation. Inter J Innov Educ Res 2014;2:133-49.

17. Sheldon RA. Green solvents for sustainable organic synthesis. State of the art Green Chem 2005;7:267-8.

18. Tanaka K. Solvent-free Organic Synthesis. Wiley-VCH: Weinheim, Germany; 2003

19. Tanaka K, Toda F. Solvent-free organic synthesis. Chem Rev 2008:100:1025-74.

20. Bose AK, Pednekar S, Ganguly SN, Chakraborty G, Manhas MS. A simplified green chemistry approach to the Biginelli reaction using 'Grindstone Chemistry'. Tetrahedron Lett 2004;45:8351-3.

21. Rothenberg G, Downie AP, Raston CL, Scott JL. Understanding solid/solid organic reactions. J Am Chem Soc 2001;123:8701-8.

22. Doxsee KM, Hutchison JE. Green organic chemistry-strategies, tools, and laboratory experiments. Brooks/Cole: Pacific Grove, CA; 2004. p. 115-9.

23. Smith JG. Organic Chemistry, McGraw-Hill: New York; 2008. p. 917-28.

24. Woodward RB, Baer H. The reaction of furan with maleic anhydride. J Am Chem Soc 1948;70:1161.

25. Rideout DC, Breslow R. Hydrophobic acceleration of diels-alder reactions. J Am Chem Soc 1980;102:7816.

26. Sandier SR, Karo W. Organic functional group preparations. Academic Press: San Diego; 1989. p. 431-76.

27. Greene TW, Wuts PGM. Protective groups in organic synthesis. Wiley: Toronto; 1999. p. 355-8.

28. Saikia L, Baruah JM, Thakur AJ. A rapid, convenient, solventless green approach for the synthesis of oximes using grindstone chemistry. Org Med Chem Lett 2011;1:12.

29. Hathaway BA. An aldol condensation experiment using a number of aldehydes and ketones. J Chem Educ 1987;64:367.

30. Bhagat S, Sharma R, Chakraborti AK. Dual-activation protocol for tandem cross aldol condensation: an easy and highly efficient synthesis of $\alpha, \alpha^{\prime}$-bis(arylmethylidene) ketones. J Mol Cat A: Chem 2006;260:235-40.

31. Phonchaiya S, Panijpan B, Rajviroongit S, Wright T, Blanchfield JT. A facile solvent-free cannizzaro reaction. J Chem Edu 2009;86:85-6.

32. Kirchhoff M, Ryan MEds. Greener approach to undergraduate chemistry experiments. Am Chem Soc 2002;25.

33. Trost BM. The atom economy-a search for synthetic efficiency. Science 1991;254:1471-7.

34. Ranu BC, Hajra A, Dey SS. A practical and green approach towards the synthesis of dihydropyrimidinases without any solvent and catalyst. Org Proc Res Dev 2002;6:817. 
35. Mahajan SS, Sharma MM, Sridhar T. Uncatalyzed oxidation of 1,5,9-cyclododecatriene with molecular oxygen. Indus Eng Chem Res 2007;46:3057-62.

36. Xie ZF, Sakai K. Construction of medium and large sized cyclic beta-keto esters (or nitriles) via one-pot three carbon ring expansion of carbocyclic beta-keto esters and its application to the synthesis of (-)-Muscone. J Org Chem 1990;55:820-6.

37. Dowd P, Choi SC. Free radical ring expansion and rearrangement of large carbocyclic rings. Tetrahedron Lett 1991;32:565-8

38. Wang DS, Wang DQ, Zhou CH. A synthesis of ( \pm )-and (R)muscone by radical ring expansion. Acta Chim Sinica 1995;53:909-15.

39. Taber DF, Straney PJ. The synthesis of laurolactam from cyclododecanone via a beckmann rearrangement. J Chem Educ 2010;87:1392.

40. Furuya Y, Ishihara K, Yamamoto H. Cyanuric chloride as a mild and active beckmann rearrangement catalyst. J Am Chem Soc 2005; $127: 11240-1$

41. Shariat M, Samsudin MW, Zakaria Z. One-pot synthesis of 2substituted 4H-3,1-benzoxazin-4-one derivatives under mild conditions using iminium cation from cyanuric chloride/ dimethylformamide as a cyclizing agent. Chem Cent J 2013;7:58.

42. Mandhare DB, Barhate VD. Development of extractive spectrophotometric method for the determination of iron (iii) with schiff base 2-[(2-hydroxyphenylimino) methyl]-4nitrophenol. Int J Curr Pharm Res 2016;8:89-91.

43. Mohan PC, Rao JV. Biological evaluation of schiff bases of new isatin derivatives for anti alzheimer's activity. Asian J Pharm Clin Res 2014;7:114-7.

44. Al-Qalaf F, Mekheimer RA, Sadek KU. Cerium (IV) ammonium nitrate (CAN) catalyzed the one-pot synthesis of 2 arylbenzothiazoles. Molecules 2008;13:2908-14.

45. Gupta AD, Sepay N, Mallik AK. An efficient microwave-assisted synthesis of 2,3-dihydroquinazolin-4(1h)-ones by a three component reaction under catalyst-and solvent-free conditions. Eur Chem Bull 2016;5:185-8.

46. Varma RS. Solvent-free organic syntheses using supported reagents and microwave irradiation. Green Chem 1999;1:43-55.

47. Kidwai M. Dry media reactions. Pure Appl Chem 2001;73:147-51.

48. Acharjee J, Ghoshal A, Ghosh SK. Microwave-assisted synthesis: need of the hour. W J Pharm Pharm Sci 2015;4:1741-9.

49. Zhaoqi Y, Pinhua S. Compare of three ways of synthesis of simple Schiff base. Molbank 2006;M514. Doi:10.3390/M514

50. Miglani S, Mishra M, Chawla P. The rapid synthesis of schiffbases without solvent under microwave irradiation and their antimicrobial activity. Der Pharma Chem 2012;4:2265-9.

51. Saha M, Roy S, Chaudhuri SK, Bhar S. Microwave assisted ammonium formate-mediated synthesis of Hanstzch dihydropyridines under the solvent-free conditions-a green protocol. Green Chem Lett Rev 2008;1:99-102.
52. Saha M, Roy S, Chaudhuri SK, Bhar S. Microwave-assisted ammonium formate-mediated Knoevenagel reaction under solvent-free conditions-a green method for $\mathrm{C}-\mathrm{C}$ bond formation. Green Chem Lett Rev 2008;1:112-3.

53. Jagwani D, Joshi P. A greener chemistry approach for the synthesis of 4-(4-hydroxyphenyl)-6-methyl-2-oxo-1,2,3,4 tetrahydro-pyrimidine-5-carboxylic acid ethyl ester. Int J Pharm Sci Res 2015;6:783-90.

54. Enamul Hassain S, Chaluvaraju KC, Niranjan MS, Zaranappa SC. Studies on microwave assisted synthesis of some schiff bases. Int Res J Pharm 2013;4:99-101.

55. Ranu BC, Hajra A, Dey SS. An efficient and green synthesis of 2arylbenzothiazoles in an ionic liquid, [pmIm] $\mathrm{Br}$ under Microwave Irradiation. Chem Lett 2004;33:274-5.

56. Kumar A, Makrandi JK. A highly efficient one step green procedure for baker venkataraman rearrangement in an aqueous medium. Heterocyclic Lett 2012;2:271-6.

57. Khunt RC, Akbari JD, Manvar AT, Tala SD, Dhaduk MF, Joshi HS et al. Green chemistry approach to the synthesis of some new trifluoromethyl-containing tetrahydropyridines under solvent free conditions. ARKIVOC 2008;9:277-84.

58. De Paolis 0, Teixeira L, Török B. Synthesis of quinolines by a solid acid-catalyzed microwave-assisted domino cyclizationaromatization approach. Tetrahedron Lett 2009;50:2939-42.

59. Mitra S, Ragunath S, Mitra A, Sae Khow O. Green chemistry in teaching laboratory: microwave-induced reactions. New Jersey's Science and Technology University; 2010. Available from: njit.edu/ mitra/green_chemistry/Content/Manualapril-2010.pdf. [Last accessed on 10 Sep 2016]

60. Fatemeh FB, Majid MH, Mina R, Ali G, Manouchehr J. Catalytic method for synthesis of aspirin by a green, efficient and recyclable solid acid catalyst (Preyssler's Anion) at room temperature. J Chin Chem Soc 2007;54:1017-20.

61. Khurana JM. Sonochemistry. Chem Educ 1990. p. 24-9.

62. Varma RS, Naicker KP. Ultrasound-accelerated permanganate oxidation: an improved procedure for the synthesis of 1,2-cis diols from olefins. Tetrahedron Lett 1998;39:7463-6.

63. Madje BR, Ubale MB, Bharad JV, Shingare MS. Alum an efficient catalyst for erlenmeyer synthesis. S Afr J Chem 2010;63:158-61.

64. Rao SS, Reddy CVR, Dubey PK. An ultrasound-mediated green synthesis of benzimidazolylthiounsaturatednitriles using water as a green solvent. Org ChemInter 2014;1-6. http://dx.doi.org/ $10.1155 / 2014 / 403803$

\section{How to cite this article}

- Meena Bhandari, Seema Raj. Practical approach to green chemistry. Int J Pharm Pharm Sci 2017;9(4):10-26. 